We thank $\mathrm{K} \mathrm{W}$ Cross, of the department of social medicine at the University of Birmingham, for help in considering the statistical implications, and the doctors who co-operated in gathering the data. We also acknowledge the valued contributions of Mrs B Hogg (Dundee) and Mrs J Dainty (Birmingham).

\section{Appendix}

Abnormal outcomes after prescription of Debendox. (Figures in parentheses show gestational age (days) at issue of first prescription (if before day 56))

In Scotland defined malformations were multiple anomalies (heart and kidney); Klippel-Feil syndrome; right leg a stump and exomphalos (56); hiatus hernia; exomphalos; diaphragmatic hernia; webbing of toes; and mongolism (33). Other abnormal outcomes were bilateral slight pes equinovarus (56); minor talipes (22); systolic murmur not fully diagnosed (45); undescended testes (53); systolic murmur, mitral area; bilateral congenital dislocation of hips; undescended testes (47); birthmark on right leg; subluxation of right hip; two cases of macerated stillbirth, cause not known; fresh stillbirth (cord round neck); stillbirth (antepartum haemorrhage) (50); intrauterine death (rhesus problem) (45); stillbirth (cord round neck); neonatal death at one month (bronchopneumonia); and neonatal death on third day $(2160 \mathrm{~g})$.

In England there were no defined malformations; other abnormalities were congenital heart disease (not fully diagnosed) (46); symptoms of hiatus hernia (51); possible mongolism; congenital heart disease (not fully diagnosed); pyloric stenosis; and stillbirth (less than $450 \mathrm{~g}$ ).

\section{References}

1 Donnai D, Harris R. Unusual fetal malformations in early pregnancy. Br Med 7 1978;i:691-2.

2 Birmingham Research Unit of the Royal College of General Practitioners. Morbidity and drugs in pregnancy. $\mathcal{F} R$ Coll Gen Pract $1975 ; 25: 631-45$.

${ }^{3}$ Crombie DL, Fleming DM. Aspects of prescribing during pregnancy. Proceedings of the Fourth National Congress of the French Perinatal Medical Society. Paris: Dubois and Renaud Librairie Arnette, 1975: 117-27.

4 Harron DWG, Griffiths K, Shanks RG. Debendox and congenital malformation in Northern Ireland. $\mathrm{Br}$ Med $\mathcal{f} 1980 ; 281: 1379-81$.

${ }^{5}$ Milkovich L, Van den Berg BJ. An evaluation of the teratogenicity of certain anti nauseant drugs. Am F Obstet Gynecol 1976;125:244-8.

6 Smithells RW, Sheppard S. Teratogenicity testing in humans: a method demonstrating safety of Bendectin. Teratology 1978;17:31-5.

(Accepted 12 May 1981)

\title{
Yersinia enterocolitica arthritis in southern Sweden: a four-year follow-up study
}

\author{
LUDMILA MARSAL，STEN WINBLAD，FRANK A WOLLHEIM
}

\begin{abstract}
Thirty-eight cases of suspected yersinia arthritis occurring in southern Sweden in 1975-6 were reviewed four to five years later. In 31 cases the diagnosis was confirmed. At follow-up three of the patients had definite ankylosing spondylitis, three radiologically confirmed sacroiliitis, three extensor tenosynovitis, five isolated articular joint disease, and 10 localised arthralgias; one patient had developed seropositive rheumatoid arthritis. Only six of the 31 patients were free of joint symptoms.

These results suggest that although the acute symptoms of yersinia arthritis disappear within 12 months, the long-term prognosis may be less favourable than previously thought.
\end{abstract}

\section{Introduction}

Reactive arthritis after infection with Yersinia enterocolitica is well recognised in some parts of the world, ${ }^{1-9}$ and the prognosis is generally assumed to be favourable. An association with HLA-B27,10-14 and evidence of transition into rheumatoid arthritis have been reported, ${ }^{3}{ }^{4}{ }^{6}$ but few systematic long-term follow-up studies have been published. We have therefore studied the outcome in a consecutive group of patients four years after acute yersinia arthritis. A surprisingly high incidence of joint symptoms was encountered.

Department of Medicine, Division of Rheumatology, and Department of Bacteriology, Malmö General Hospital, University of Lund, Malmö, Sweden

LUDMILA MARSAL, MD, registrar in rheumatology

STEN WINBLAD, MD, emeritus professor of bacteriology

FRANK A WOLLHEIM, MD, senior lecturer in rheumatology

\section{Patients and methods}

We reviewed 45 consecutive patients in whom during 1975-6 suspected reactive arthritis had been diagnosed and tests on sera had yielded positive agglutinin titres against $Y$ enterocolitica type 3 . Of these patients, 38 were traced and re-examined clinically. $X$-ray pictures were taken from painful joints. Blood was analysed for haemoglobin concentration, erythrocyte sedimentation rate, liver enzyme activities, and serum creatinine concentration. Urine analysis was performed. In addition, a plasma sample was analysed for concentrations of albumin, fibrinogen, $\alpha_{1}$-antitrypsin, orosomucoid, haptoglobin, caeruloplasmin, IgG, IgA, IgM, C3, and C4.

\section{Results}

\section{INITIAL DISEASE}

In 31 of the 38 patients the diagnosis of yersinia arthritis was confirmed by a history of unequivocal acute arthritis documented by their doctors and concomitant agglutination test titres against $Y$ enterocolitica type 3 of 160 or more. In the remaining seven patients yersinia arthritis could not be confirmed. The age range was 26-76 years and the mean 48 years. Nineteen of the patients were women and 12 men (table I). In 20 cases the onset of the disease occurred during September to December (table II). The affected joints were knees (19 instances); ankles (12); fingers (15); wrists (nine); toes (nine); shoulders (four); elbows (four); and low back (four). Over four joints were affected in 13 patients. The acute joint symptoms lasted from six weeks to 12 months.

\section{FOLLOW-UP INVESTIGATION}

Of the six patients who were free of joint symptoms and had normal physical findings, one (case 27) developed an atrioventricular conduction block, probably after yersinia myocarditis. In the remaining 25 patients joint complaints and findings varied (table I). A 
TABLE I-Clinical symptoms at follow-up examination

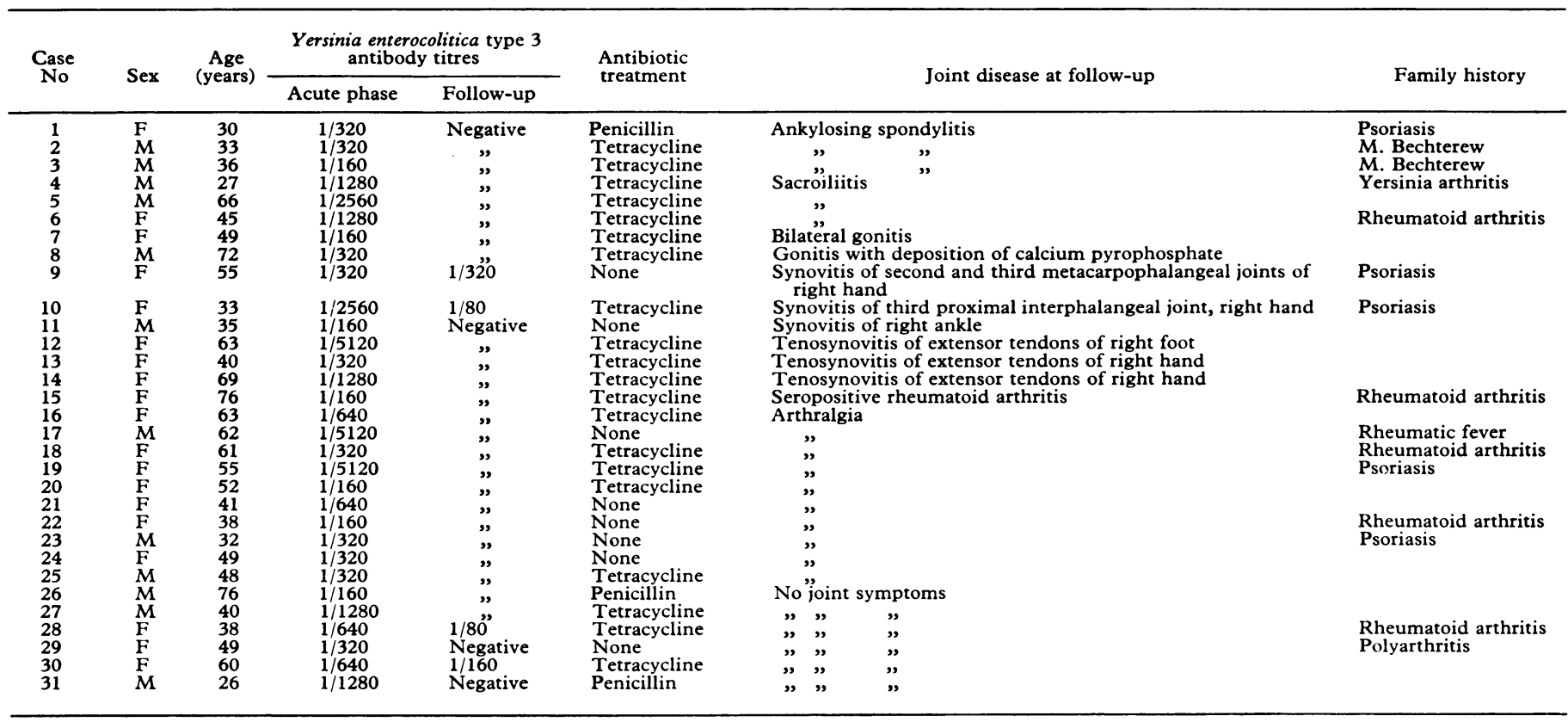

TABLE II-Month of onset of yersinia arthritis in 31 acute cases

\begin{tabular}{lccccccccccccccc}
\hline Month &. & $\ldots$ & J & F & M & A & M & J & J & A & S & O & N & D & Total \\
\hline No of cases.. & $\ldots$ & 3 & 2 & & 1 & 2 & 1 & & 2 & 7 & 7 & 4 & 2 & 31
\end{tabular}

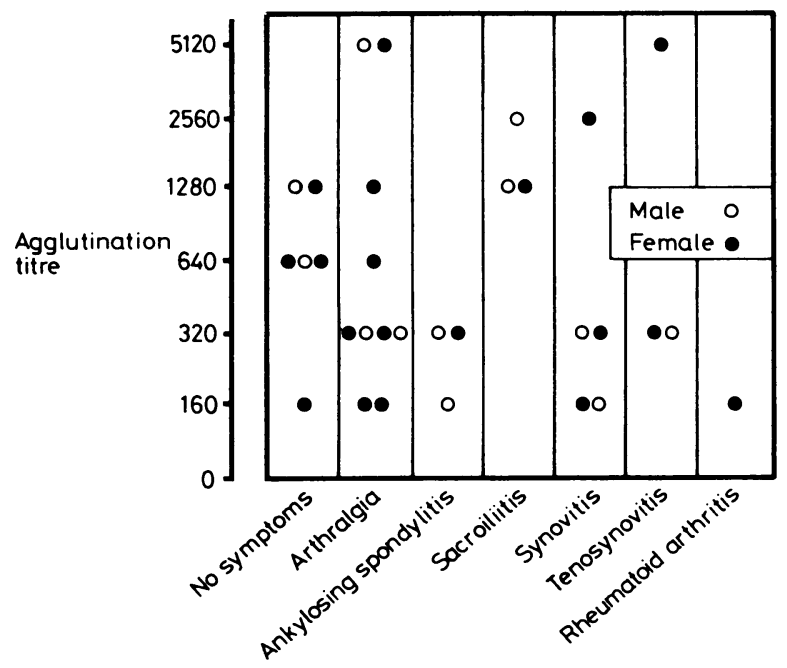

FIG 1-Highest $\boldsymbol{Y}$ enterocolitica agglutinin titres in relation to follow-up findings.

woman aged 30 and a man of 33 had had ankylosing spondylitis diagnosed at the ages of 20 and 22 respectively. In a 36-year-old man ankylosing spondylitis was diagnosed during the follow-up period. $\mathrm{He}$ also had a history of iridocyclitis. In two men and one woman sacroiliitis was diagnosed at follow-up. One of the men had suffered from two attacks of balanitis and one attack of urinary tract infection. One patient with gonitis underwent an unsuccessful synovectomy. Another had chondrocalcinosis visible on radiography. Three patients had monarthritis of fingers and ankle, and three extensor tenosynovitis in wrists and ankle. A 76-year-old woman had developed seropositive erosive rheumatoid arthritis in the follow up period. Ten patients had longstanding arthralgia in joints previously affected with acute yersinia arthritis. One of these also had psoriasis and a history of

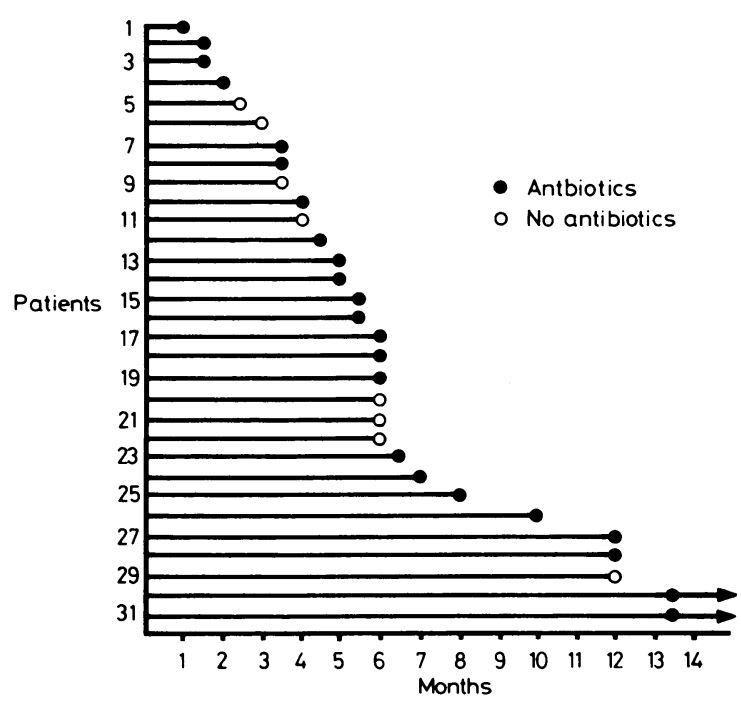

FIG 2-Durations of acute symptoms in relation to antibiotic treatment.

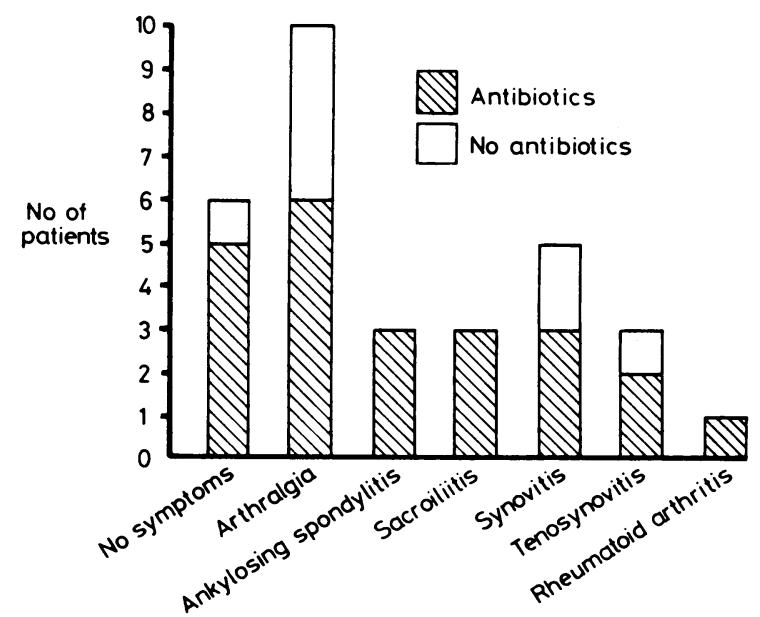

FIG 3-Follow-up findings in relation to antibiotic treatment. 
iritis, and one gave a positive Waaler-Rose test. Four patients had positive $Y$ enterocolitica agglutinin titres at follow-up; two of these had monarthritis and two were among the unsymptomatic cases.

Blood tests and urine analysis gave normal results with the exceptions mentioned above. Apart from the patient with seropositive erosive rheumatoid arthritis no peripheral joint-erosions were seen.

The highest $Y$ enterocolitica agglutinin titre did not correlate with the findings at the follow-up examination (fig 1). The initial antibiotic treatment did not appreciably influence outcome or duration of symptoms (figs 2 and 3 ).

\section{Discussion}

These findings confirm that yersinia arthritis is characterised by a self-limiting acute phase. ${ }^{1-3}$ The complicating arthritis mainly affects carriers of HLA-B27.10-14 Although spondylitis is overrepresented in all carriers of HLA-B27, the risk for this complication is much higher if psoriasis, Crohn's disease, or ulcerative colitis is also present. ${ }^{15}$ The question arises whether yersinia arthritis also increases this risk, and our study suggests that it does, with symptomatic sacroiliitis in $20 \%$ of cases. This represents a minimum figure, since for ethical reasons only patients with local complaints were submitted to pelvic radiography.

The occurrence of rheumatoid arthritis in one patient is interesting in view of claims that yersinia arthritis may be a factor in rheumatoid arthritis and even its causative agent. ${ }^{3}{ }^{4}$ The cases identified as rheumatoid arthritis in one of the studies, however, cannot be accepted as such on the given evidence. Rheumatoid arthritis is not associated with HLA-B27, and in our opinion there is no evidence that $Y$ enterocolitica as such is an aetiological agent in rheumatoid arthritis. Nevertheless, yersinia infection may change the natural course of rheumatoid arthritis into a more aggressive form by an unspecific polyclonal B-cell stimulation. ${ }^{16} 17$

Ankylosing spondylitis may cause peripheral arthritis, and it is questionable whether the three patients in the presented series actually had yersinia arthritis plus ankylosing spondylitis or just an exacerbation of ankylosing spondylitis. In view of the high titres against $Y$ enterocolitica in all patients and diarrhoea in one, we think it probable that these patients had acquired yersinia arthritis and thus had developed two concomitant HLA-B27-associated conditions. Definite proof for such a theory, however, would be provided only by finding $Y$ enterocolitica antigen in diseased synovial tissue.

We cannot explain the large number of patients with arthralgic complaints at follow-up as we did not examine a control population. It was, however, remarkable to find as many as one-third of the patients with such symptoms. We were impressed by how distinctly the patients' arthralgias were localised to certain joints, and these patients did not seem to belong to the group with multiple symptoms found in a general population. The pathophysiology and ultimate outcome of yersinia arthritis should be investigated further.

This study was supported by grants from Riksförbundet mot Reumatism and Alfred Österlunds Stiftelse.

Requests for reprints should be addressed to: Dr L Marsal, Department of Medicine, Malmö General Hospital, S-214 01 Malmö, Sweden.

\section{References}

1 Ahvonen A, Sievers $\mathrm{K}$, Aho $\mathrm{K}$. Arthritis associated with Yersinia enterocolitica infection. Acta Rheumatologica Scandinavica 1969;15: 232-53.

2 Winblad S. Arthritis associated with Yersinia enterocolitica infections. Scand 7 Infect Dis $1975 ; 7: 191-5$.

${ }^{3}$ Kalliomäki JL, Leino R. Follow-up studies of joint complications in yersiniosis. Acta Med Scand 1979;205:521-5.

4 Anker E, Osnes M. Yersinia-artritt. Tidsskr Nor Laegeforen 1978;98:502-5.

5 Arvaston B, Damgaard K, Winblad S. Clinical symptoms of infection with Yersinia enterocolitica. Scand $\mathcal{F}$ Infect Dis 1971;3:37-40.

${ }^{6}$ Jarner D, Jarlöv NV, Larsen JH. Yersinia arthritis and chronic collagenosis. Ugeskr Laeger 1977;139:1481-4.

${ }^{7}$ Larsen HJ. Yersinia enterocolitica infections and their most frequent complications. Ugeskr Laeger 1977;139:2627-32.

${ }^{8}$ Hällström K, Sairanen E, Ohela K. A pilot clinical study on yersinioses in south-eastern Finland. Acta Med Scand 1972;191:485-91.

${ }^{9}$ Laitinen O, Tuuhea J, Ahvonen P. Polyarthritis associated with Yersinia enterocolitica infection. Ann Rheum Dis 1972 ;31 :34-9.

10 Aho $\mathrm{K}$, Ahvonen $\mathrm{P}$, Juvakoski $\mathrm{T}$, Kousa $\mathrm{M}$, Leirisalo $\mathrm{M}$, Laitinen $\mathrm{O}$. Immune responses in Yersinia-associated reactive arthritis. Ann Rheum Dis $1979 ; 38: 123-6$.

11 Leirisalo M, Laitinen O, Tillikainen A. HLA phenotypes in patients with rheumatic fever, rheumatic heart disease and yersinia arthritis. f Rheumatol $1977 ; 4$ :suppl 3:78-83.

12 Laitinen O, Leirisalo M, Skylv G. Relation between HLA-B27 and clinical features in patients with yersinia arthritis. Arthritis Rheum $1977 ; 20: 1121-4$

${ }^{13}$ Baier R, Puppel H, Hahn E. Infections caused by Yersinia enterocolitica. Dtsch Med Wochenschr 1979;104:281-5.

14 Ford DK. Yersinia-induced arthritis and Reiter's syndrome. Ann Rheum Dis $1979 ; 38: 127-8$.

15 Brewerton DA. Many genes, many clinical features. Ann Rheum Dis $1979 ; 38: 145-8$.

${ }^{16}$ Möller E, Ström H, Al-Balaghi S. Role of polyclonal activation in specific immune responses. Scand f Immunol 1980;12:177-82.

17 Banck G, Forsgren A. Many bacterial species are mitogenic for human blood B lymphocytes. Scand $\mathcal{F}$ Immunol 1978;8:347-54.

(Accepted 1 May 1981)
CAMOMILE is so well known everywhere, that it is but lost time and labour to describe it. The virtues thereof are as follow.

A decoction made of Camomile, and drank, takes away all pains and stitches in the side. The flowers of Camomile beaten, and made up into balls with Gill, drive away all sorts of agues, if the part grieved be anointed with that oil, taken from the flowers, from the crown of the head to the sole of the foot, and afterwards laid to sweat in his bed, and that he sweats well. This is Nechessor, an Egyptian's, medicine. It is profitable for all sorts of agues that come either from phlegm, or melancholy, or from an inflammation of the bowels, being applied when the humours causing them shall be concocted; and there is nothing more profitable to the sides and region of the liver and spleen than it. The bathing with a decoction of Camomile takes away weariness, eases pains, to what part of the body soever they be applied. It comforts the sinews that are over-strained, mollifies all swellings: It moderately comforts all parts that have need of warmth, digests and dissolves whatsoever has need thereof, by a wonderful speedy property. It eases all pains of the cholic and stone, and all pains and torments of the belly, and gently provokes urine. The flowers boiled in posset-drink provokes sweat, and helps to expel all colds, aches, and pains whatsoever, and is an excellent help to bring down women's courses. Syrup made of the juice of Camomile, with the flowers, in white wine, is a remedy against the jaundice and dropsy. The flowers boiled in lye, are good to wash the head, and comfort both it and the brain. The oil made of the flowers of Camomile, is much used against all hard swellings, pains or aches, shrinking of the sinews, or cramps, or pains in the joints, or any other part of the body. Being used in clysters, it helps to dissolve the wind and pains in the belly; anointed also, it helps stitches and pains in the sides.

Nechessor saith, the Egyptians dedicated it to the Sun, because it cured agues, and they were like enough to do it, for they were the arrantest apes in their religion that I ever read of. Bachinus, Bena, and Lobel, commend the syrup made of the juice of it and sugar, taken inwardly, to be excellent for the spleen. Also this is certain, that it most wonderfully breaks the stone: Some take it in syrup or decoction, others inject the juice of it into the bladder with a syringe. My opinion is, that the salt of it, taken half a dram in the morning in a little white or Rhenish wine, is better than either; that it is excellent for the stone, appears in this which I have seen tried, viz., That a stone that has been taken out of the body of a man being wrapped in Camomile, will in time dissolve, and in a little time too. (Nicholas Culpeper (1616-54) The Complete Herbal, 1850.) 